\title{
Autophagy is associated with a robust specific transcriptional signature in breast cancer subtypes
}

\author{
Céline Grandvallet ${ }^{1,5}$, Jean Paul Feugeas ${ }^{1}$, Franck Monnien ${ }^{1,4}$, Gilles Despouy ${ }^{1}$, \\ Perez Valérie ${ }^{1}$, Guittaut Michaël ${ }^{1,2}$, Eric Hervouet ${ }^{1,2,3, *}$, Paul Peixoto ${ }^{1,3, *}$ \\ ${ }^{1}$ Univ. Bourgogne Franche-Comté, INSERM, EFS BFC, UMR1098, Interactions Hôte-Greffon-Tumeur/Ingénierie Cellulaire et \\ Génique, F-25000 Besançon, France \\ ${ }^{2}$ DImaCell Platform, Univ. Bourgogne Franche-Comté, F-25000 Besançon, France \\ ${ }^{3}$ EPIGENEXP Platform, Univ. Bourgogne Franche-Comté, F-25000 Besançon, France \\ ${ }^{4}$ Tumorothèque de Besançon, Univ. Bourgogne Franche-Comté, F-25000 Besançon, France \\ ${ }^{5} \mathrm{CHRU}$ de Besançon, Univ. Bourgogne Franche-Comté, F-25000 Besançon, France \\ * These authors have contributed equally to this work \\ Correspondence to: Paul Peixoto, email: paul.peixoto@univ-fcomte.fr \\ Keywords: breast cancer, autophagy, transcriptome, gene expression signature \\ Received: August 04, $2020 \quad$ Accepted: September 13, $2020 \quad$ Published: October 06, 2020
}

Copyright: ( 2020 Grandvallet et al. This is an open-access article distributed under the terms of the Creative Commons Attribution License (CC BY 3.0), which permits unrestricted use, distribution, and reproduction in any medium, provided the original author and source are credited.

\section{ABSTRACT}

Previous works have described that autophagy could be associated to both pro- and anti-cancer properties according to numerous factors, such as the gene considered, the step of autophagy involved or the cancer model used. These data might be explained by the fact that some autophagy-related genes may be involved in other cellular processes and therefore differently regulated according to the type or the grade of the tumor. Indeed, using different approaches of transcriptome analysis in breast cancers, and further confirmation using digital PCR, we identified a specific signature of autophagy gene expression associated to Luminal A or Triple Negative Breast Cancers (TNBC). Moreover, we confirmed that ATG5, an autophagy gene specifically expressed in TNBC, favored cell migration, whereas BECN1, an autophagy gene specifically associated with ER-positive breast cancers, induced opposite effects. We also showed that overall inhibition of autophagy promoted cell migration suggesting that the role of individual ATG genes in cancer phenotypes was not strictly dependent of their function during autophagy. Finally, our work led to the identification of TXNIP1 as a potential biomarker associated to autophagy induction in breast cancers. This gene could become an essential tool to quantify autophagy levels in fixed biopsies, sort tumors according to their autophagy levels and determine the best therapeutic treatment.

\section{INTRODUCTION}

According to the concept of autophagy network proposed by Behrends et al. in 2010, it has been described that autophagy, a lysosome-mediated degradation pathway, involves more than 40 ATG proteins (Autophagy-related proteins) and is regulated by more than 100 other proteins [1]. Autophagy regulates cell homeostasis and survival by controlling the degradation and recycling of protein aggregates, or organelles, in a multistep process.
Each autophagy stage is associated to and mediated by specific proteins: i) Autophagy induction is driven by the core proteins ULK1 - ULK2 (Unc-51 Like Autophagy Activating Kinase 1 and 2), ATG11 and ATG13 and regulated by the mTOR-related proteins; ii) Autophagy initiation is directed by the core proteins UVRAG (UV Radiation Resistance Associated), VPS15, BECN1 (BECLIN-1), VPS34, ATG2A/B, ATG9A/B, ATG14 and the WIPI family (WD Repeat Domain, Phosphoinositide Interacting); iii) Autophagy elongation is mainly regulated 
by the ATG4 family, ATG8 family, ATG3, ATG5, ATG7, ATG10, ATG12 and the ATG16L family); iv) Lysosome elongation is mediated by the LAMP family and V-ATPase and v) Fusion of the lysosome with the autophagosome is induced by the core proteins RAB38 and VAMP8. All these steps are regulated by dozen of kinases, GTPases, ligases and chaperon proteins. Besides the existence of a non-selective autophagy process during which the autophagosome randomly engulfs and degrades cell components, it has also been described the existence of a selective autophagy which is driven by specific adaptor proteins, such as SQSTM1 (Sequestosome 1)/P62, BNIP3L (BCL2 Interacting Protein 3 Like)/NIX, NBR1 (Neighbor Of BRCA1 Gene 1), ALFY (AutophagyLinked FYVE Protein), PARKIN (Parkinson Protein 2, E3 Ubiquitin Protein Ligase) or PINK1 (PTEN Induced Kinase 1) to lead to the degradation of specific targets, such as ubiquitinated or aggregated proteins, damaged mitochondria, peroxisomes, and bacteria [2]. The role of autophagy in cancer is complex and paradoxical. On one hand, anti-tumor properties of autophagy have been associated to the first steps of cancer since it can prevent the transformation of healthy cells into cancer cells [3, 4]. On the other hand, autophagy could also favor tumor growth by conferring resistance to chemotherapies and promoting cell survival in a tumor microenvironment described to be poor in nutriments.

Breast Cancer (BC) is a heterogeneous disease with more than 2 million new cases each year in the world and with an incidence of 126 per 100,000 women in the USA. Despite increased therapy efficiency and earlier diagnosis, $\mathrm{BC}$ remains associated with a mortality rate of more than 22 per 100,000 women in this country. The usual molecular classification of $\mathrm{BC}$ is based on the quantification of the expression of main proteins, such as estrogen receptor (ER) (coded by the gene ESR1), progesterone receptor (PR), HER2 (human epidermal growth factor receptor 2) and KI67, a marker of proliferation. Consequently, four groups of $\mathrm{BC}$ have been described: Luminal $\mathrm{A}\left(\mathrm{ER}^{+}\right.$or $\left.\mathrm{PR}^{+}, \mathrm{KI} 67^{-}, \mathrm{HER} 2^{-}\right)$, Luminal B $\left(\mathrm{ER}^{+}\right.$or $\mathrm{PR}^{+}, \mathrm{KI} 7^{+}$or HER2 ${ }^{+}$), HER2 (ER', HER 2+) and triple negative (TNBC, ER', PR', HER2-) (for a review, see [5]). During the last decade or so, many studies demonstrated the major role of autophagy in Breast Cancer during tumor progression, tumor dormancy, metastasis progression or the apparition of resistance to treatments $[6,7]$.

The evaluation of autophagy in patient samples remains a challenging question due to the difficulty of quantifying a dynamic mechanism in non-living fixed tissues. Although autophagy was considered for decades as a dynamic protein process regulated by post-translational modifications, it appears now that many autophagy-related genes are regulated at the transcriptional level, as well. Regarding individual gene expression, a high expression of MAP1LC3B (usually called LC3B) has been associated to poor prognosis in triple negative breast cancer TNBC
[8-10]. On the contrary, BECN1 has been considered as a tumor suppressor gene $[4,11]$ and the expression of an ATG8 family member, GABARAPL1, has been associated to a good prognosis in $\mathrm{BC}$ [12-16]. These data therefore strongly suggest that proteins involved in different steps of autophagy (e.g. phagophore initiation or elongation) may present different and even opposite roles during breast tumorigenesis. An additional problem is the lack of knowledge on this matter since very little is known about the pattern of expression of autophagy-related genes in $\mathrm{BC}$.

Altogether, these informations led us to hypothesize and demonstrate, using a metadata analysis of more than 150 autophagy-related genes followed by the biological confirmation of our Biocomputing data in a $\mathrm{BC}$ cohort, that $\mathrm{BC}$ subgroups are clearly associated to a specific autophagy transcriptional signature. Moreover, our results also unequivocally showed that different factors of the autophagy pathway, belonging to this signature, were directly involved in cancer aggressiveness and prognosis via both dependent and independent autophagy functions.

\section{RESULTS}

Since, in previous studies, autophagy has been associated to both pro- and anti-cancer properties according to the cancer models used, we suggested that these differences could be linked to different and specific $A T G$ gene expression. To answer this question, we first looked for a transcriptional autophagy signature in $\mathrm{BC}$ subgroups using 166 genes directly involved in autophagy, or associated to the autophagy network according to Behrends et al. [1] (Figure 1). We therefore used 5345 retrospective transcriptomes, obtained from raw data downloaded from public databases, which were then divided in 2 series corresponding to HG-U133A arrays and HG-U133 plus2 arrays. In each of the series, we counted more than 500 triple negative, 300 HER2 and 1800 Luminal tumors. The quantification of positivity or negativity of four genes (ER, PGR, KI67, HER2) produced robust classifications which were concordant with the Prediction Analysis of Microarray 50 (PAM50) classification based upon centroids [17]. A list of 50 genes related to autophagy and presenting the highest differential expression was used to build a heatmap. Our analysis clearly showed that $A T G$ genes were differentially expressed between BC subgroups (Figure 1A). As expected, a similar profile was obtained between the HGU133A arrays and the HG-U133 plus2 arrays (Figure 1B) confirming that a specific transcriptional autophagy signature was associated with $\mathrm{BC}$ subgroups. Venn diagrams confirmed that most of genes were similarly clusterized in both heatmaps (Figure 1C).

Amongst this signature, we selected 6 genes presenting the most important differences in microarrays plus2 (and confirmed in other transcriptome analyses) 
A

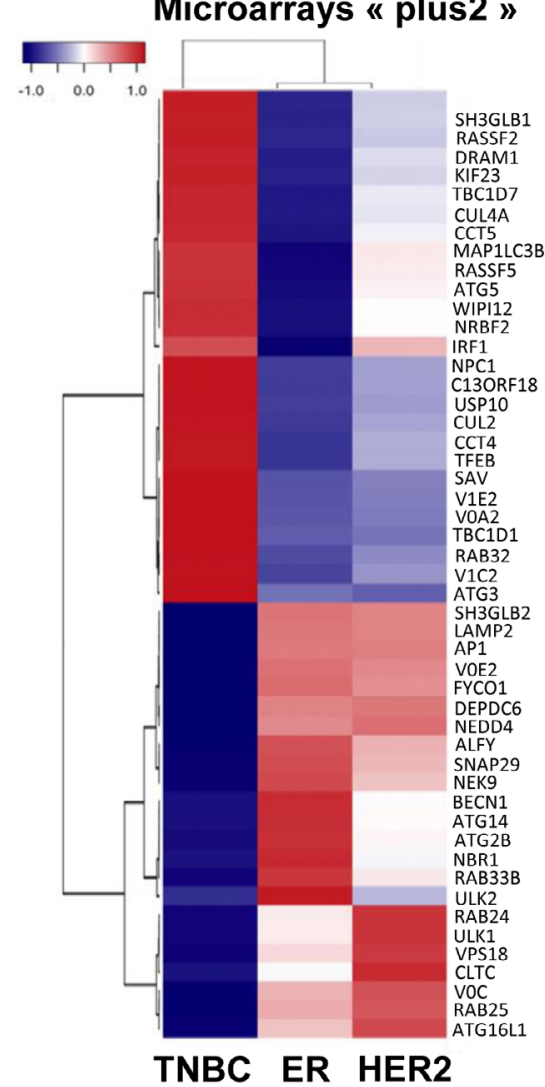

C
B Microarrays « A "

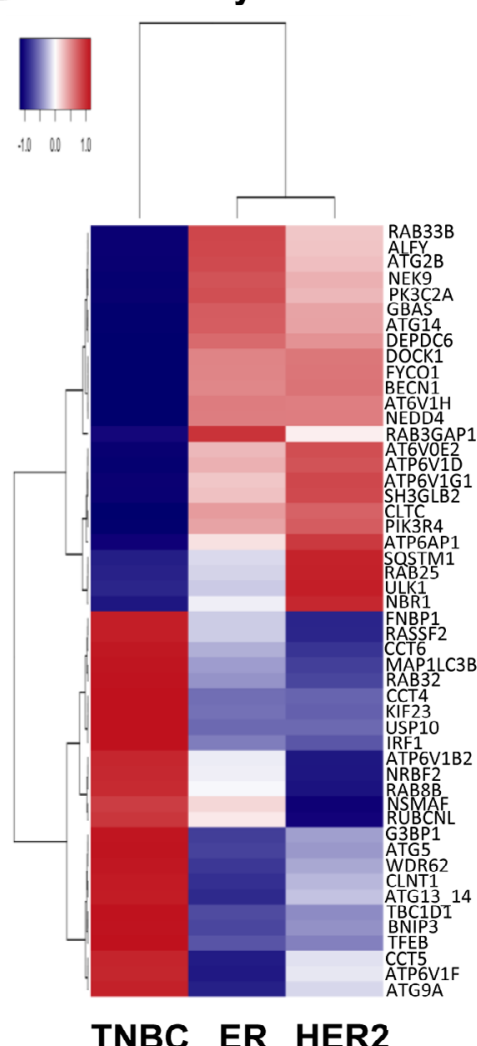

TNBC ER HER2
D TCGA
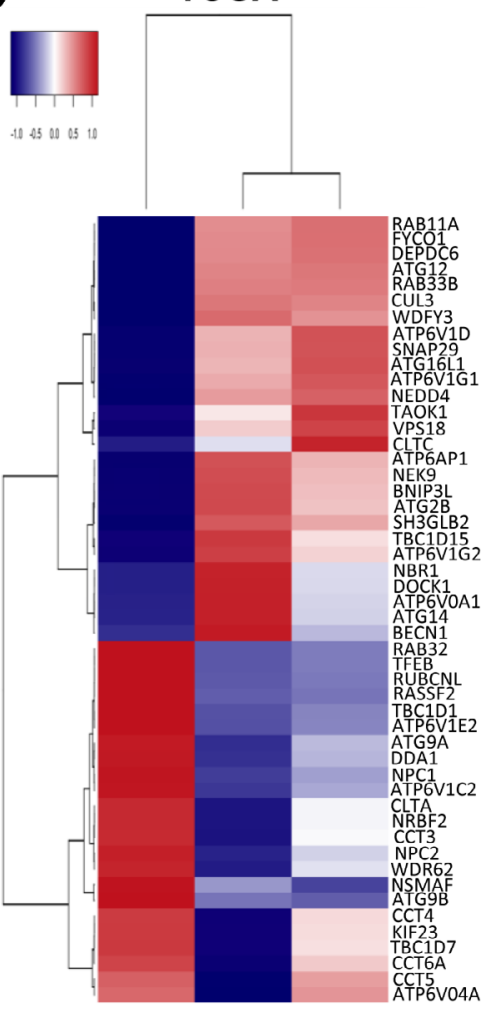

TNBC ER HER2

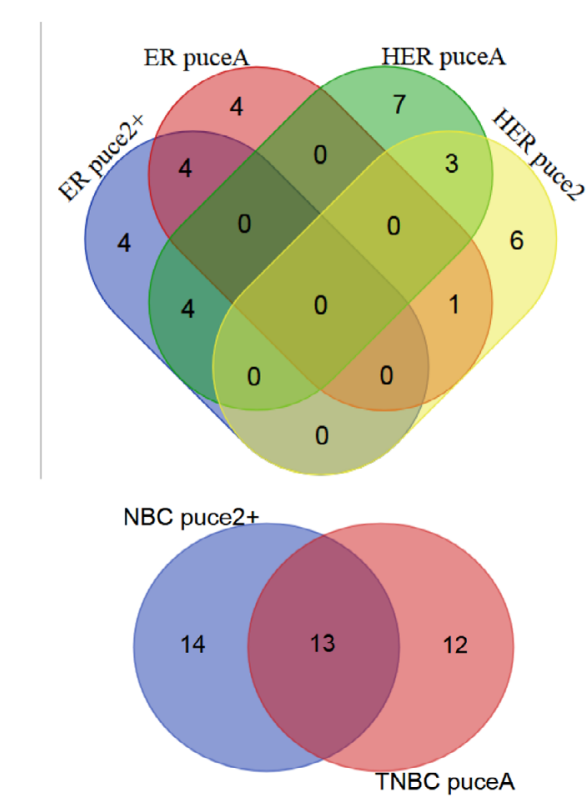

\begin{tabular}{|c|c|c|}
\hline Names & total & elements \\
\hline $\begin{array}{l}\text { TNBC PuCe2+ TNBC } \\
\text { puceA }\end{array}$ & $\mid 13$ & LC38 ATG5 TBC1D1 CCT4 NRBF2 RAB32 CCTS TFEB RASSSF2 USP10 RFF 1 KIF23 CCT6 \\
\hline $\begin{array}{l}\text { ER puce2+ ER } \\
\text { puceA }\end{array}$ & 4 & ALFY ATG14 RAB33B ATG2B \\
\hline $\begin{array}{l}\text { ER puce 2+ HER } \\
\text { puceA }\end{array}$ & $\mid$ & BECN1 NBR1 FYCO1 SH3GLB2 \\
\hline $\begin{array}{l}\text { ER puceA HER } \\
\text { puce2 }\end{array}$ & $\mid 1$ & DEPDC6 \\
\hline $\begin{array}{l}\text { HER pUCE2 HER } \\
\text { pUCEA }\end{array}$ & 3 & ULK1 CLTC RAB25 \\
\hline TNBC puce2+ & 14 & $\begin{array}{l}\text { CUL4A ATG3 TBC1D7 NPC1 WPR SH3GLB1 DRAM1 V1C2 V0A2 CUL2 SAV V1E2 RASSF5 } \\
\text { C13ORF18 }\end{array}$ \\
\hline TNBC puceA & $\mid 12$ & $\begin{array}{l}\text { ATPEV1F WDR62 BNP3 G3BP1 ATG13 ATG9A RUBCNL FNBP1 ATP6V1B2 CLINT1 NSMAF } \\
\text { RABBB }\end{array}$ \\
\hline ER puce2+ & 4 & SNAP29 ULK2 LAMP2 VOE2 \\
\hline ER puceA & 4 & RAB3GAP1 GBAS NEK9 PIK3C2A \\
\hline HER puceA & 7 & DOCK1 ATP6AP1 ATP6V1D PIK3R4 SOSTM1 ATP6V1G1 ATP6VOE2 \\
\hline HER puce2 & 6 & RAB24 AP1 VOC NEDO4 VPS 18 ATG16L1 \\
\hline
\end{tabular}

\section{TNBC ER HER2}

Figure 1: Breast cancer subgroups are associated with a specific autophagy gene expression signature. 2691 and 2806 samples, respectively, and the most variable autophagy genes were hierarchically classified according to correlations between gene expressions normalized from HG-U133 plus2 arrays A. or microarray "A" B. and BC groups. The color Dark red means relative high expression while the color Dark blue means relative low expression. C. Venn diagrams comparing the identified genes identified in HGU133 plus2 arrays and microarrays in regards to BC subtypes. D. Heatmap representing the most variable autophagy genes described from the data extracted from 1022 normalized BC RNA-seq (TCGA). 
and which were representative of the BC subgroups: $I R F 1, L C 3 B$ and $A T G 5$ whose expression was increased in TNBC; $B E C N 1$ and $A T G 2 B$ whose expression was increased in the ER group (HER+ or -) and finally, ULK1 whose expression was elevated in ER and HER2 groups compared to TNBC. To confirm whether our signature, and particularly our selection of genes, could be used as a prediction tool, we next quantified the expression of these 6 genes using the droplet digital PCR (ddPCR) technology in a new independent $\mathrm{BC}$ cohort. Amongst our 64 BC samples, 38 were qualified for ddPCR (with a housekeeping gene expression of $h s T B P>0.3$ copies / $\mu 1)$. The $\mathrm{BC}$ subtypes were then classified using both IHC criteria (ER, PR and HER status) and the expression of KI67 and FOXA1 analyzed with the ddPCR (Supplementary Figure 1). Remarkably, the ddPCR data, obtained during the analysis of this new cohort, confirmed that $B E C N 1$ and $A T G 2 B$ expressions were the highest in ER tumors while $I R F 1, L C 3 B$ and $A T G 5$ expressions were increased in TNBC (Figure 2). The absence of confirmation of the association of $U L K 1$ expression with the HER subgroup using ddPCR was probably due to the low number of HER samples available.

Since the role of autophagy in cancer has been frequently studied in $\mathrm{BC}$ cell models, we next compared the expression of autophagy genes in BC cells to our BC signature (Figure 3A). As expected, the autophagy profile of the model cell lines studied was strongly correlated
A
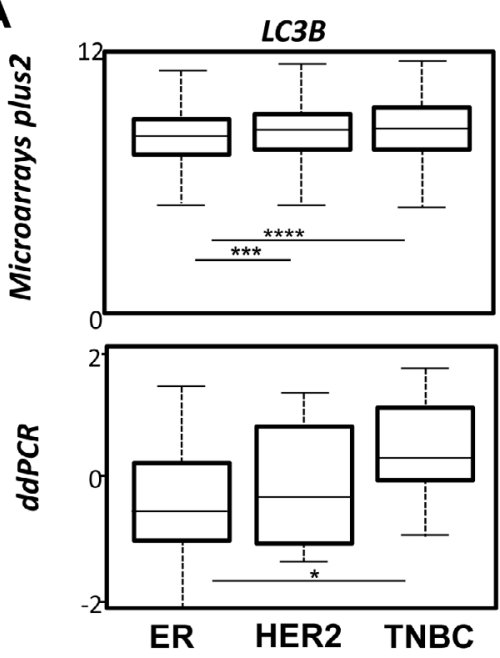

B
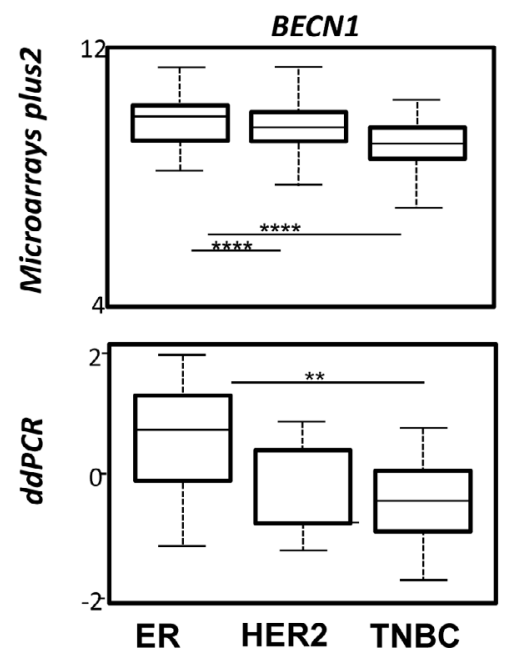
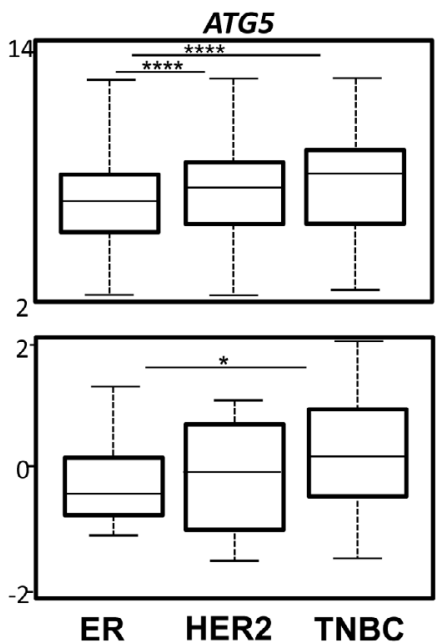

ER HER2 TNBC
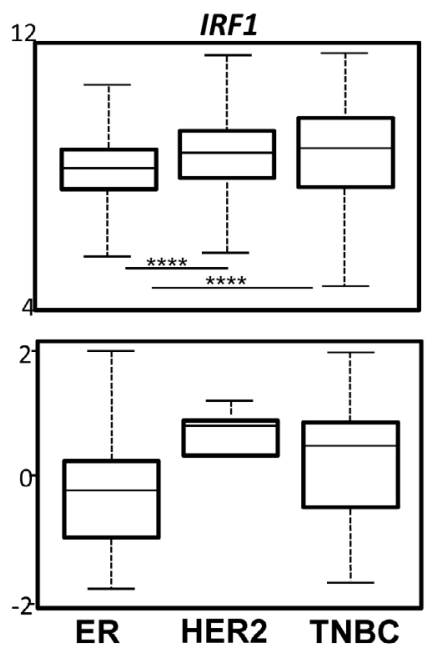
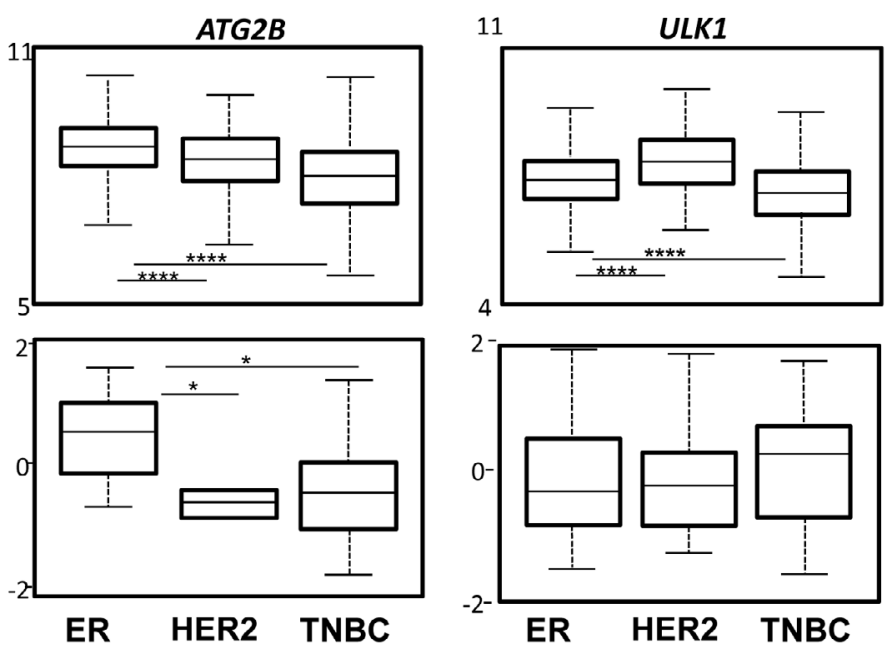

Figure 2: Confirmation of the specific autophagy gene expression signature using ddPCR in an independent cohort of BC. A. Expression quantification boxes built from the HG-U133 plus2 data for $L C 3 B, A T G 5$ and IRF1 gene expressions (top). Confirmation of the results obtained using ddPCR in an independent cohort (bottom). B. Expression quantification boxes built from the HG-U133 plus2 data for $B E C N 1, A T G 2 B$ and $U L K 1$ gene expressions (top). Confirmation of the results obtained using ddPCR in an independent cohort (bottom). 
to our transcriptional autophagy signature in regards of their BC classification [18]. For example, IRF1, LC $3 B$ and $A T G 5$ expressions were low while $U L K 1, A T G 2 B$, $B E C N 1$ expressions were elevated in ER-positive T47D cells whereas opposite results were observed for the TNBC MDA-MB-468 cell line. When we quantified gene expression in these cell lines (values of $I R F 1, L C 3 B$, $A T G 5$ minus the values obtained for $A T G 2 B, B C N 1$ ), the cell lines were perfectly discriminated between ER and TNBC subgroups (Figure 3B). Again, when cell lines were classified in regards to their LumA or TNBC status, the differences obtained were highly significant $(p<0.0001)$. Indeed, all negative scores corresponded to LumA cell lines whereas positive scores belonged to the TNBC group. Specific profiles of $A T G 2 B, B E C N 1$ and $A T G 5$ expressions were then confirmed using qRT-PCR (Figure 3C) in MCF-7 and MDA-MB-231 cell lines, thus confirming the robustness of the heatmap data.

Since TNBC present a much more aggressive phenotype than ER-positive $\mathrm{BC}$, we next wondered whether this transcriptional signature could be associated to good or bad prognosis. To do so, we used the KMplotter database to analyze the survival rate of $\mathrm{BC}$ patients in regards to their expression of the 6 genes representative
A

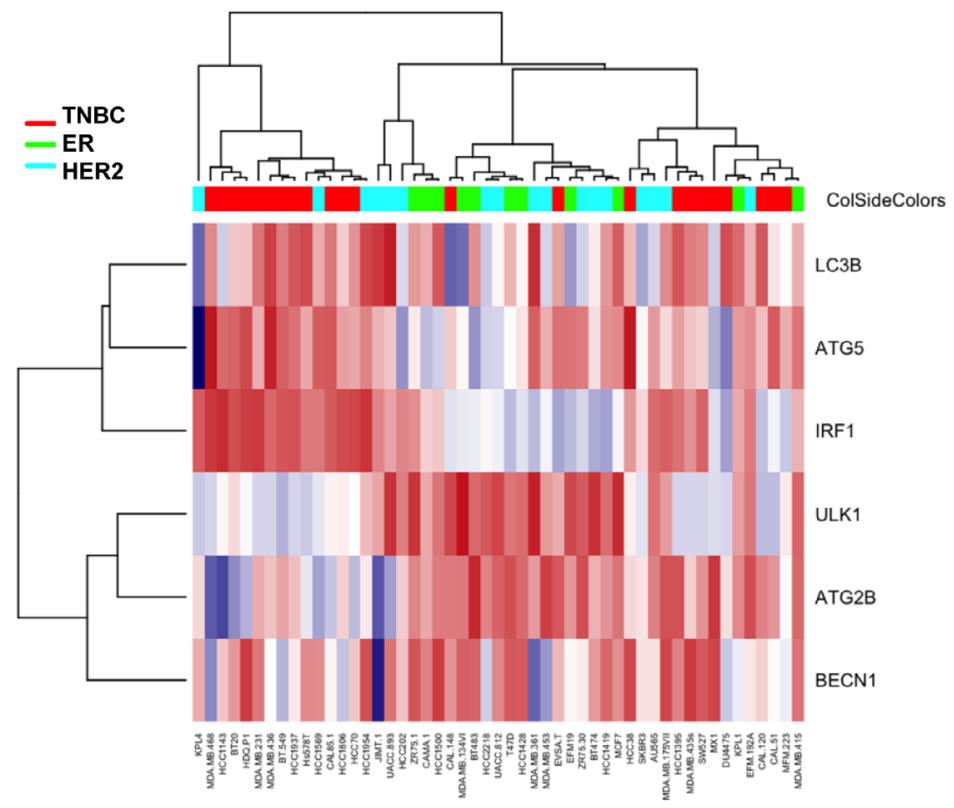

B

\begin{tabular}{|c|c|c|}
\hline Score & Cell line & Classification \\
\hline-14 & MDA134VI & ER \\
\hline-12 & T47D & ER \\
\hline-11 & BT483 & ER \\
\hline-11 & HCC1428 & ER \\
\hline-7 & ZR75 & ER \\
\hline-5 & CAMA1 & ER \\
\hline-2 & MCF7 & ER \\
\hline-3 & MDA-MB-415 & ER \\
\hline-3 & MDA-MB175VII & ER \\
\hline 1 & MCC1500 & TNBC \\
\hline 1 & MDA435S & TNBC \\
\hline 6 & HCC38 & TNBC \\
\hline 6 & MDAMB231 & TNBC \\
\hline 8 & HS578T & TNBC \\
\hline 9 & HCC1143 & TNBC \\
\hline 9 & BT20 & TNBC \\
\hline 10 & BT549 & TNBC \\
\hline 10 & HCC1937 & TNBC \\
\hline 11 & $\mathrm{HCC7O}$ & TNBC \\
\hline 12 & MDAMB436 & TNBC \\
\hline 19 & MDAMB468 & TNBC \\
\hline
\end{tabular}

C
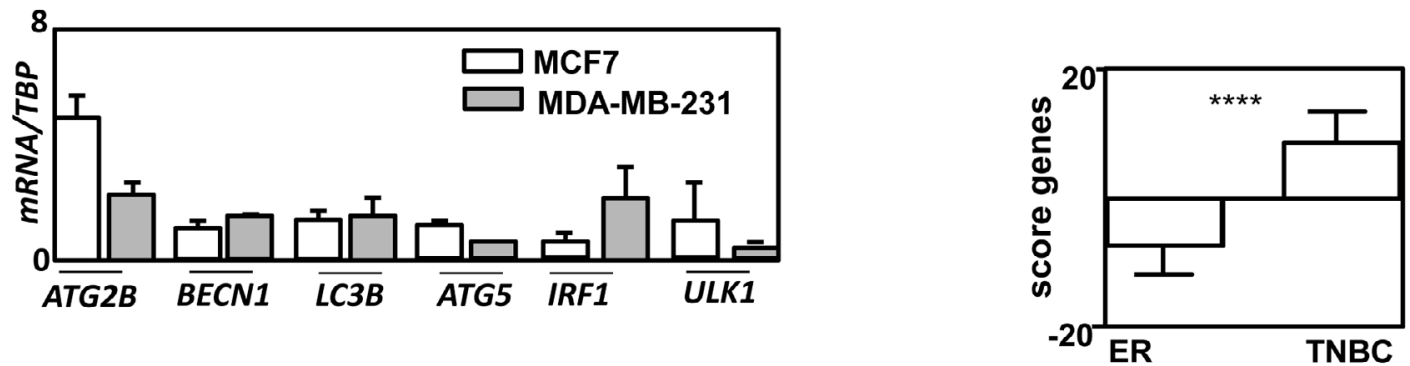

Figure 3: The restricted specific autophagy gene expression signature in $\mathrm{BC}$ groups efficiently discriminates $\mathrm{BC}$ cell lines. A. Heatmap representing the selected autophagy signature ( $L C 3 B, A T G 5, I R F 1, U L K 1, A T G 2 B, B E C N 1)$ which was obtained from data of normalized HG-U133 plus2 with BC cell lines. B. The score of -6 to +6 according to heatmap intensity (from blue to red) was calculated as follow: values of $I R F 1, L C 3 B, A T G 5$ minus values of $A T G 2 B, B C N 1$. TNBC and ER cell lines were perfectly discriminated with this score (bottom). C. RT-qPCR confirmation of ATG2B, BECN1, LC3B, ATG5, IRF1 and ULK1 expressions. 
A
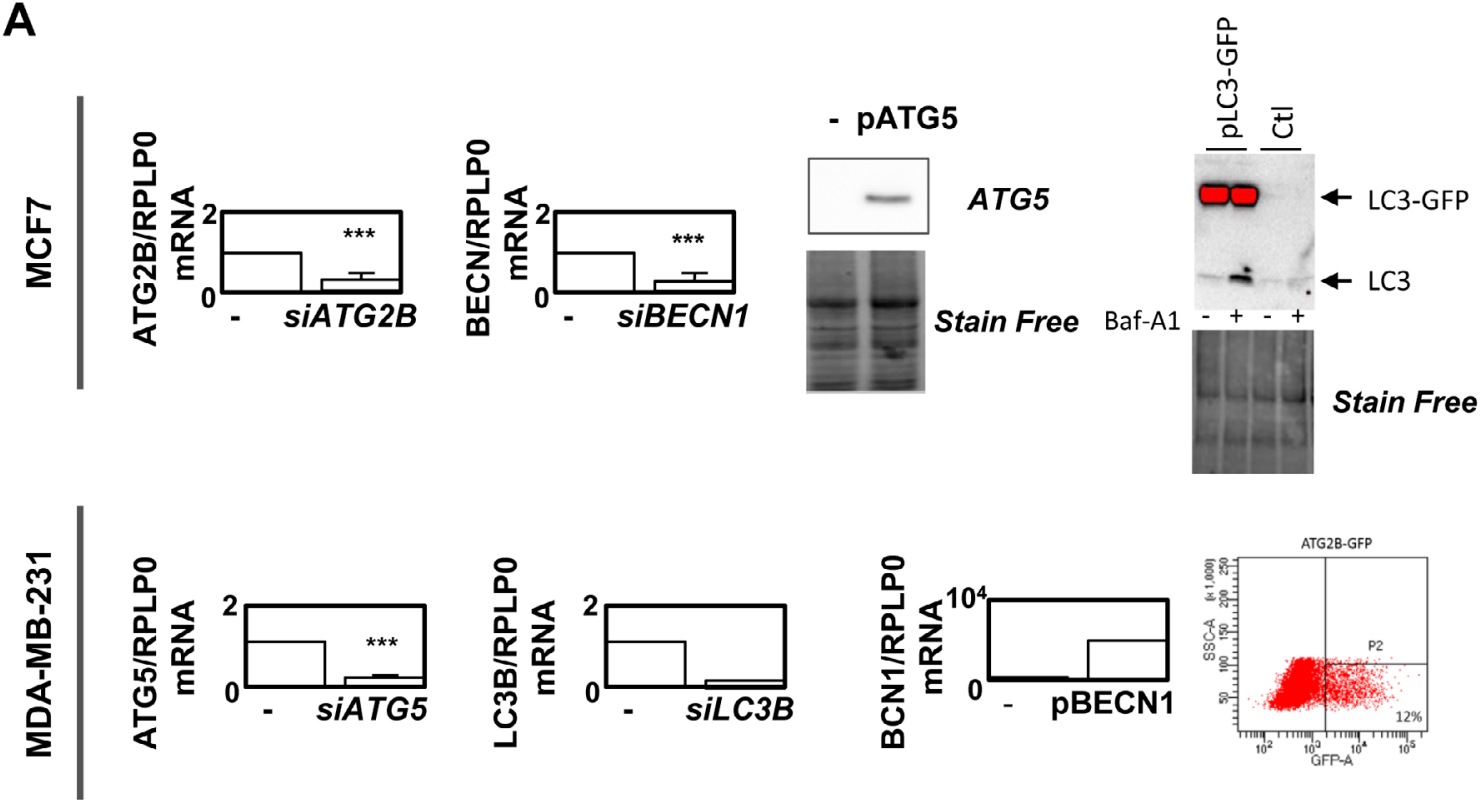

B
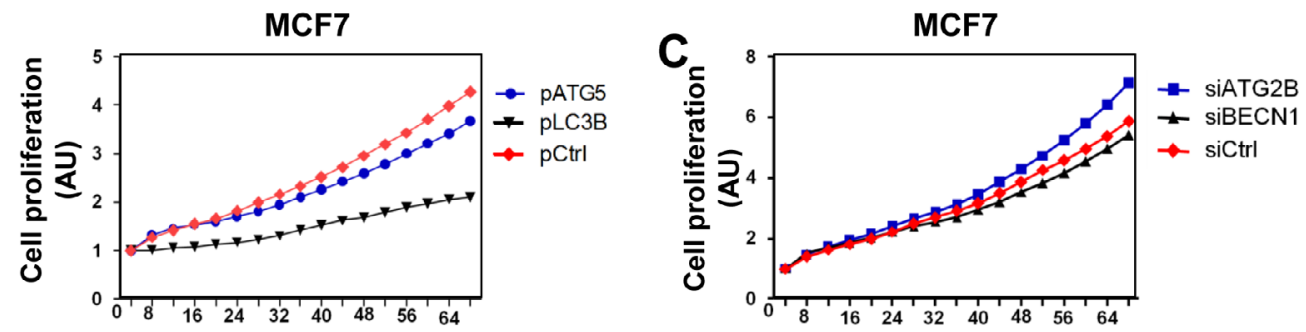

D

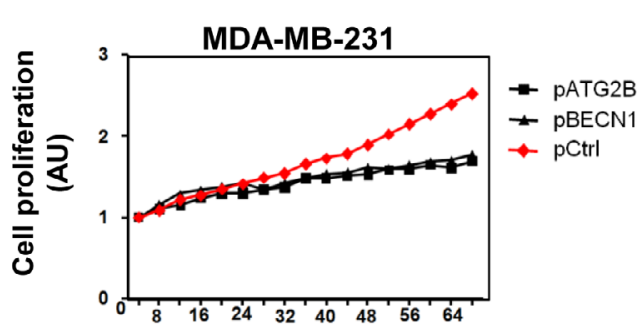

E

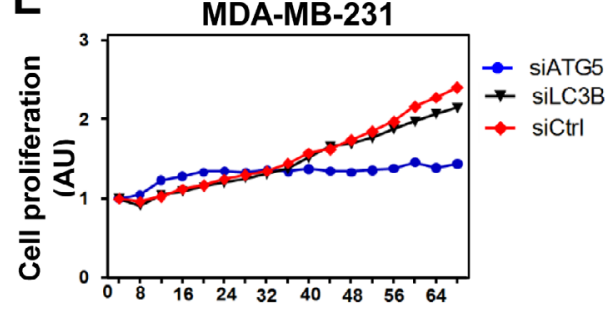

$\mathbf{F}$
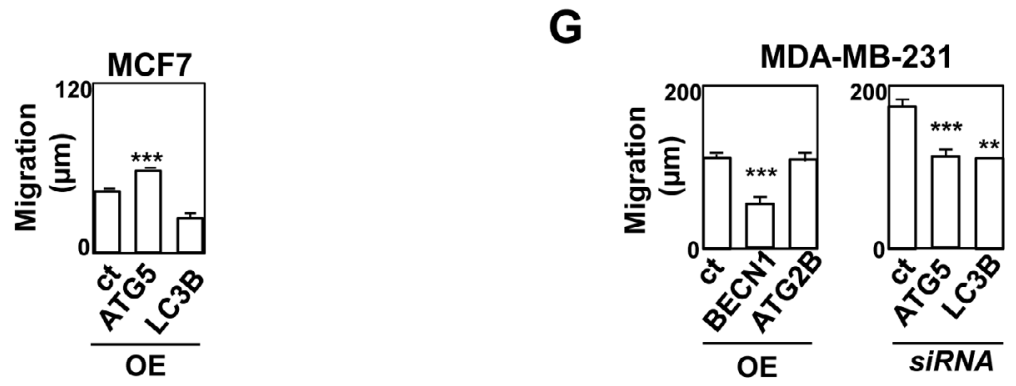

Figure 4: The modulation of gene expression of genes from the specific autophagy signature in BC groups affects cancer-related phenotypes. A. Overexpression or inhibition of $L C 3 B, A T G 5, B E C N 1, A T G 2 B$ expressions were confirmed using RT-qPCR, Western-blotting or flux cytometry analysis of MCF-7 or MDA-MB-231 cells. B-E. Cell proliferation monitored using the Incucyte technology in MCF-7 or MDA-MB-231 cells after overexpression or inhibition of the expression of the selected genes. F-G. Cell migration measured using a wound healing assay after $8 \mathrm{~h}$ in MCF-7 or MDA-MB-231 cells after overexpression or inhibition of the expression of the selected genes. 
of our autophagy signature (Supplementary Figures 2-3). As expected and in agreement to our $\mathrm{BC}$ signature, a high expression of $B E C N 1, A T G 2 B$ and $U L K 1$ was associated with a good prognosis, whereas the expression of $A T G 5$ was associated with a poor prognosis. No difference was observed for $L C 3 B$ and, to our surprise, a high expression of $I R F 1$ was also associated to a good prognosis. Similarly, Kaplan-Meier analysis of other genes differentially expressed between TNBC and ERpositive $\mathrm{BC}$ (Figure 1) also determined the survival rate of patients. Indeed, a high expression of ATG3, CCT4, CCT5 and $C C T 6$, whose expression was also up-regulated in TNBC (Figure 1), were associated with a poor prognosis (Supplementary Figure 3), whereas a high expression of $A T G 14$ and $F Y C O 1$, whose expression was up-regulated in ER-positive BC (Figure 1), were associated with a good prognosis. We next used a TNBC gene signature/ER gene signature ratio to determine whether this value would further narrow the survival rate of patients. Our analysis showed that patients with a high $A T G 5 / B E C N 1$ ratio indeed presented a lower survival rate (159.5 months) compared to the prediction using $B E C N 1$ expression alone (185 months) or ATG5 expression alone (189 months) (Supplementary Figure 4). A smaller difference was also observed with the $A T G 5 / A T G 2 B$ ratio (75 months) compared to $A T G 2 B$ expression alone (79.5 months). These data strongly suggested that our $A T G$ signature could be used to predict $\mathrm{BC}$ prognosis.

When we looked at relapse-free survival at 5 years in an independent cohort using the ROC Plotter database [19], we observed that endocrine therapy, anti-HER therapy and chemotherapy were more efficient in ER, HER+ and TNBC cancers, respectively. No differences were observed for $I R F 1$ expression but we observed that a high BECN1 expression was associated $(p<0.0001)$ with a higher response to endocrine therapy (Supplementary Figure 5) compared to the ER signature. A similar, but not significant tendency, was also observed for $A T G 2 B$. A high $A T G 5$ expression seemed inversely correlated to a response to endocrine therapy $(p=0.066)$ and to an antiHER therapy $(p<0.01)$, but correlated to a significant response to chemotherapy according to the TNBC signature. Similarly, $L C 3 B$ expression inversely correlated to both endocrine $(p<0.01)$ and anti-HER $(p<0.0001)$ therapy responses. Altogether, these data argued that our genes were specific markers of these BC subgroups but could also be used to predict prognosis, as well as treatment responses.

Since our gene signature was associated to prognosis and that these genes all belonged to the autophagy process, we next asked whether they were directly involved in cancer-related phenotypes. We decided to focus our analysis on $A T G 5, L C 3 B, A T G 2 B$ and BECN1 genes because they strongly discriminated ER and TNBC BC (Figures 1 and 2). We therefore overexpressed (OE) or silenced the expression of these genes in $\mathrm{BC}$ models,
ER-positive MCF-7 and TNBC MDA-MB-231 cell lines, using transfection of plasmids or siRNA. $A T G 2 B$, whose expression was increased in LumA, and $L C 3 B$, whose expression was increased in TNBC, were selected accordingly to our BC signature (Figure 4A). Surprisingly, overexpression of $L C 3 B$ reduced MCF-7 cell proliferation but as described above, although $L C 3 B$ expression was found associated with TNBC in our heatmap, this gene was not discriminant for prognosis (Supplementary Figure 3). No significant effects were observed following overexpression of $A T G 5$ or inhibition of $A T G 2 B$ or $B E C N 1$ expression in these cells (Figure 4B-4C). Regarding the MDA-MB-231 cells, in agreement with our BC signature, overexpression of $B E C N 1$ or $A T G 2 B$ decreased cell proliferation whereas inhibition of $A T G 5$, but not $L C 3 B$, also reduced cell proliferation in this TNBC cell model (Figure 4D-4E). We next measured cell migration which is a feature much more representative of cancer cell aggressiveness than in vitro cell proliferation. In MCF7 , overexpression of $A T G 5$, but not $L C 3 B$, increased cell migration (Figure 4F). In MDA-MB-231 cells, which present a higher basal migration rate, inhibition of ATG5 expression decreased cell migration but inhibition of $A T G 5$ or $L C 3 B$ expression reduced cell migration, as well (Figure 4F). Taken together, these data strongly suggested that autophagy genes, linked to our BC signature, were, at least partially, involved in cancer aggressiveness.

Nevertheless, we hypothesized that apparent contradictory results may be explained by their specific role in the autophagy process or by autophagy-independent functions. We therefore used MCF-7 and MDA-MB-231 cell lines, which both presented a high basal autophagy flux, quantified by the measure of LC3B-II accumulation following BafA1 or EBSS treatment, compared to other cells lines such as MDA-MB-468 which is, for example, not inducible by EBSS (Figure 5A). The blockage of autophagy by BafA1 increased cell migration, whereas an induction of autophagy by EBSS strongly inhibited cell migration in these cell lines (Figure 5B). A combination of EBSS and BafA1 partially restored cell migration. These data strongly supported the idea that autophagy inhibited cell migration in both cell lines. We next analyzed the effects of the modulation of $A T G 5, B E C N 1, A T G 2 B$ and $L C 3 B$ genes on autophagy levels. Interestingly, an inhibition of the expression of these 4 genes dramatically decreased autophagy flux (Figure 5C). Combined together, all these data argued that autophagy decreased cell migration in $\mathrm{BC}$ cell lines and that the autophagy genes specifically associated to $\mathrm{BC}$ subgroups exerted their proand anti-cancer properties in both an autophagy-dependent and independent manner.

We next wondered whether $A T G$ expression could also be used to evaluate autophagy both in fixed cancer biopsies. Since autophagy modulation may be a useful tool to regulate $\mathrm{BC}$ growth or progression, it would be important to better evaluate autophagy levels in tumors 
A

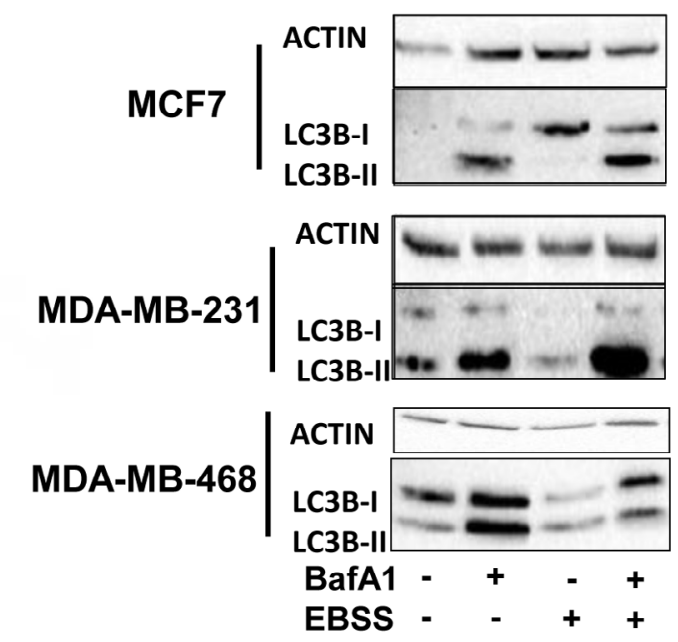

B
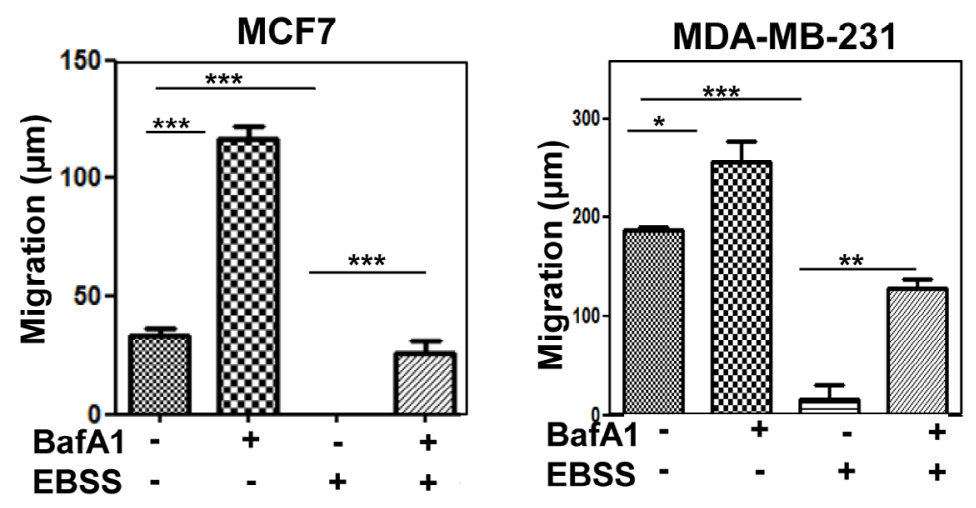

C

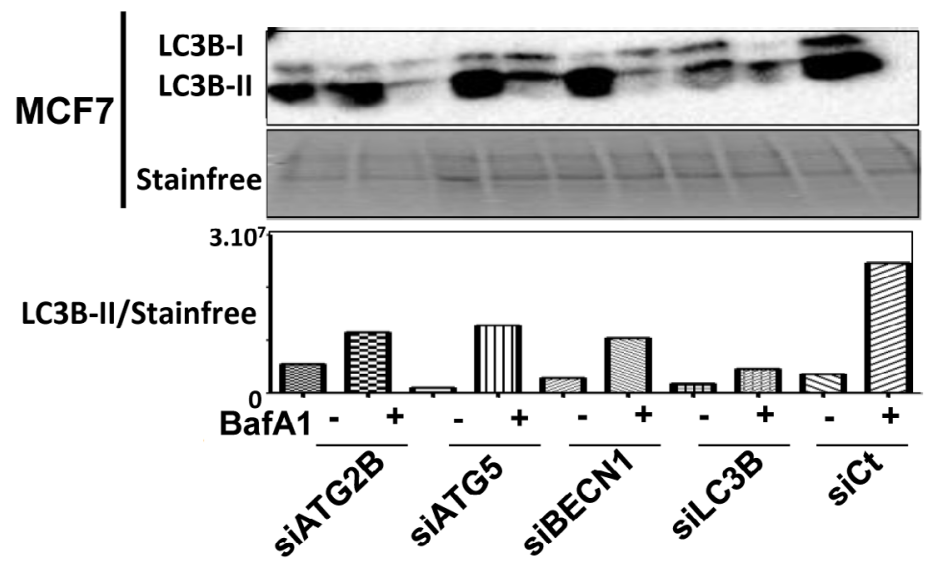

Figure 5: Autophagy directly affects cancer-related phenotypes. A. Efficient basal autophagy and EBSS-induced autophagy weres confirmed using WB (LC3B-II accumulation) in both MCF-7 and MDA-MB-231 cells. B. Cell migration measured using a wound healing assay after $8 \mathrm{~h}$ in MCF-7 or MDA-MB-231 cells, previously treated, or not, with BafA1 (autophagy blockage) and/or EBSS (autophagy induction). C. Effect of the inhibition of the expression of the selected genes on autophagy flux. 
in order to develop and provide personalized therapies. However, autophagy is a dynamic flux process, and it is difficult to evaluate the level of autophagy in patients from the analysis of fixed BC biopsies. Indeed, a high level of LC3B-II may be a sign of a strong induction of autophagy, related to a high production of autophagosomes, as well as a blockage of the autophagy flux, linked to a loss of an efficient elimination of autophagosomes by lysosomes leading to their accumulation. We therefore asked whether $A T G$ expression and our $\mathrm{BC}$ signature would help to determine the levels of autophagy flux. To do so, we decided to look for a transcriptional signature of the induction of autophagy and we performed RNA-seq experiments using MDA-MB-231 (TNBC) cells treated with EBSS in order to induce autophagy for 4 to $48 \mathrm{~h}$. A heatmap of the most differentially expressed $A T G$ genes is presented in Figure 6A. Interestingly, when $A T G$ genes were classified using a heatmap, it appeared that $A T G 5$ expression increased after $4 \mathrm{~h}$ of EBSS treatment and then progressively decreased during $48 \mathrm{~h}$. $A T G 2 B$, $B E C N 1$ and $L C 3 B$ expression were also increased during the treatment. According to our BC autophagy gene signature, these data suggested that autophagy might be more induced in ER-positive BC than in TNBC. It is noteworthy that the expression profiles of $\angle C 3 B$ and $A T G 5$ were then confirmed using qRT-PCR following autophagy induction with EBSS (Figure 6B). However, since these genes belonged to our $\mathrm{BC}$ signature and were associated to specific BC groups, we also searched, in our total transcriptome, for an independent gene which could be added to our signature to evaluate autophagy induction independently of the BC subgroup. Following this research, we selected TXNIP whose expression appeared strongly induced after EBSS treatment in our 2 independent RNA-seq analyses (data not shown), and which appeared to be one of the most robust differentially expressed genes. We also confirmed this important increase of TXNIP expression using qRT-PCR in both MCF-7 and MDA-MB-231 cells (Figure 6C), and therefore demonstrated that TXNIP expression was not related to ER-positive or TNBC BC (Figure 6D).

As expected, a KM-plotter analysis revealed that patients presenting a high expression of TXNIP were associated with the best prognosis ( $p=1 \mathrm{E}-13$ ) (Figure 6E). Interestingly, when TXNIP expression was independently analyzed in ER-positive BC or in TNBC subgroups, this biomarker remained discriminant for prognosis showing that this gene could be a good marker of autophagy induction (Supplementary Figure 6B-6C). Similarly, using ROC plotter, a high expression of TXNIP was associated with a significant higher response to any chemotherapy ( $p$ $=3.2 \mathrm{E}-2)$ and seemed to be also associated with a higher response to endocrine therapy $(p=0.08)$ confirming that TXNIP expression was associated with a good prognosis, independently of the grade of the BC (Supplementary Figure $6 C$ ). On the opposite, although $L C 3 B, A T G 5$,
$A T G 2 B$ and $B E C N 1$ expressions were strongly associated to a specific $\mathrm{BC}$ group and that these genes regulated cell migration, none of these genes alone was discriminant for RFS in ER-positive BC or in TNBC subgroups. Our data therefore clearly showed that the quantification of $A T G 5$, $L C 3 B, A T G 2 B, B E C N 1$ and TXNIP expressions would help to better discriminate and classify BC tumors.

\section{DISCUSSION}

Since autophagy is a complex mechanism previously associated with both pro- and anti-tumor properties, we decided to analyze the expression of more than 150 autophagy-related genes in a meta-analysis of $\mathrm{BC}$ transcriptomes to avoid bias of selection which could explain apparent contradictory published data. Interestingly, transcript levels of autophagy genes were not evenly distributed amongst the different tumor subtypes and we identified a transcriptional autophagy signature (ATG5, LC3B, ATG2B, BECN1, IRF1) of BC concordant in microarrays A, microarrays plus2, RNA-seq TCGA and this signature was also confirmed in a small independent cohort using ddPCR.

Amongst the genes found in our transcriptional autophagy signature, $B E C N 1$ expression has already been shown to be modified in BC. Indeed, according to previous reports describing $B E C N 1$ as a tumor suppressor gene, we found that $B E C N 1$ expression was correlated with the ER-positive group and that overexpression of this gene reduced both cell proliferation and migration $[4,11,20]$. These data were also in agreement with previous works showing that $B E C N 1$ expression was inversely correlated to the $\mathrm{BC}$ grade and that ER-negative $\mathrm{BC}$ were associated with low BECN1 expression [21] [22]. These data, and our transcriptional signature in $\mathrm{BC}$, strongly suggested that proteins involved in autophagy induction were protective against cancer phenotypes. In agreement with our observations, a meta-analysis using 23 independent studies recently concluded that a high $B E C N 1$ expression was a favorable predictive factor for overall survival (OS) in $\mathrm{BC}$, gastric cancers and lymphomas, whereas high levels of $L C 3 B$ were inversely correlated with OS in $\mathrm{BC}$ [23]. Very little is known about the role of $A T G 2 B$ in cancer, but a decreased expression of this gene linked to DNA methylation in invasive ductal carcinomas might participate in BC tumorigenesis [24]. Moreover, frequent mutations in the $A T G 2 B$ gene were also reported in other cancers [25].

On the opposite, our autophagy signature was associated with an increased expression of $L C 3 B, A T G 3$ and $A T G 5$ (and CCT4-6) in TNBC suggesting that proteins associated to the elongation step of autophagy were in favor of tumorigenesis (Supplementary Figure 7). How these differences could be involved in tumorigenesis and how the expression of these genes could be linked to ER expression remain unknown and should be explored in the 
A

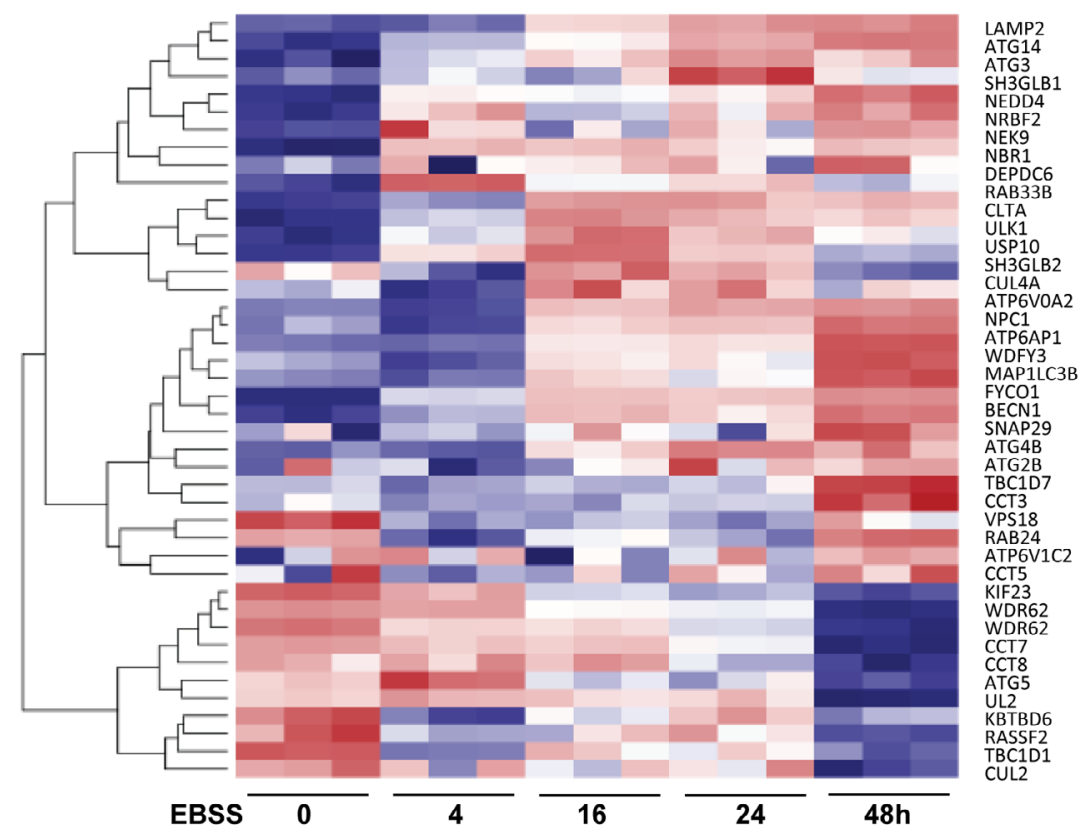

B

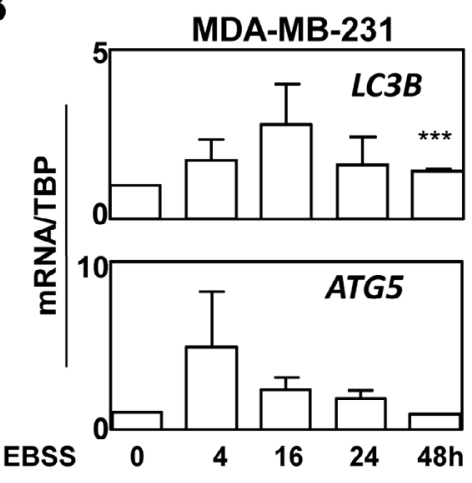

C

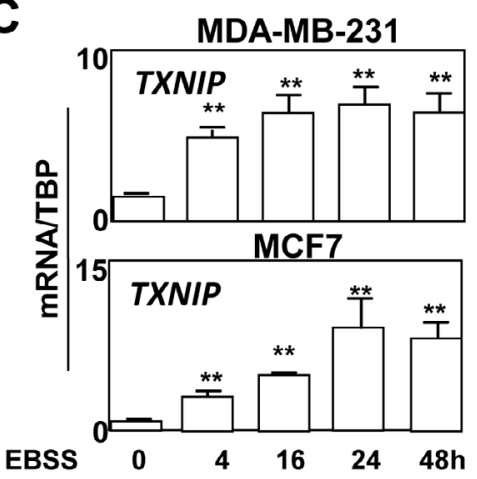

D
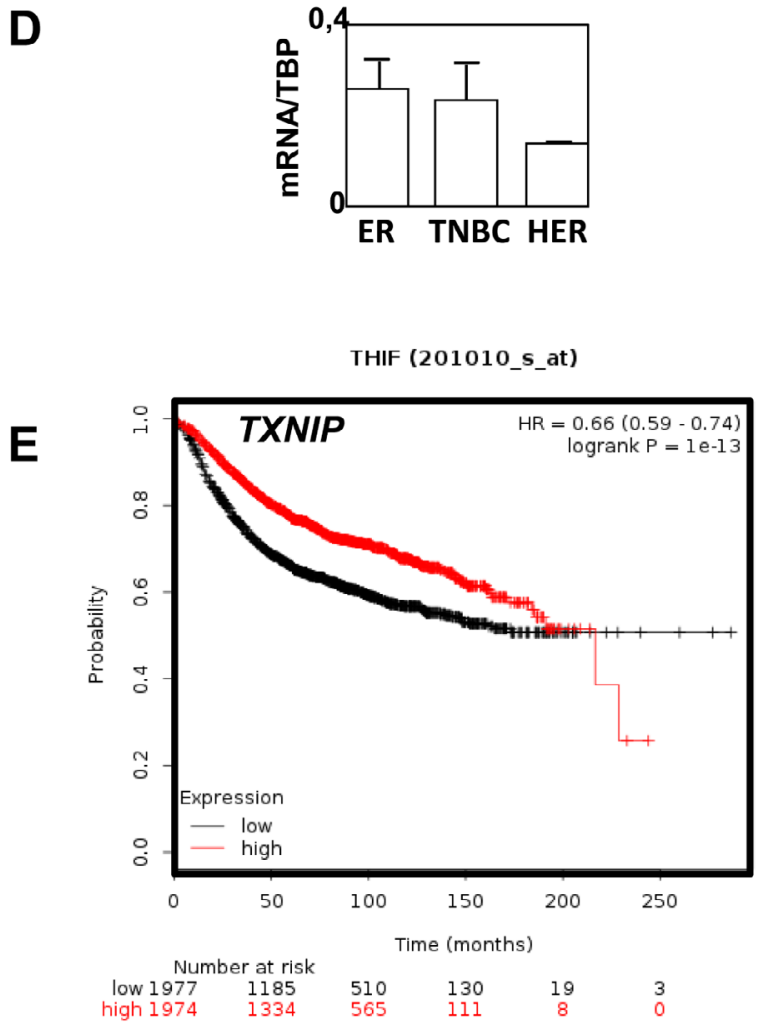

Figure 6: ATG BC signature and TXNIP expressions are markers of autophagy induction. A. Heatmap with the 40 most affected ATG-related genes in MDA-MB-231 cells treated with EBSS for 0 to $48 \mathrm{~h}$ to induce autophagy. B-E. B. Modulation of mRNA expression level of LC3B and ATG5 during autophagy in MDA-MB-231. C. A progressive increase in TXNIP expression was confirmed using RT-qPCR in MCF7 and MDA-MB-231. D. mRNA expression level of TXNIP demonstrating than TXNIP expression is independent of BC subgroup. E. Kaplan Meier data analysis revealed a significant better prognosis for patients presenting a high TXNIP expression. 
future. We know that the expression of $L C 3 B$ expression, at both mRNA and protein levels, has been previously associated to TNBC $[9,26]$ but different studies reported contradictory results regarding ATG5 expression [27, 28]. Indeed, a high $A T G 5$ expression measured by IHC has been associated with disease free survival in BC [28], whereas a high $A T G 5$ mRNA expression was correlated with shorter OS in AML [29]. Similarly, expression of both $L C 3 B$ and $A T G 5$ were promoted by hypoxia in a HIF-1-dependent manner in gliomas or prostate cancer cells [30, 31]. Moreover, inhibition of ATG5 expression in glioma cell models strongly reduced cell mobility with increased chemosensitivity under hypoxia suggesting that this gene was also associated with aggressiveness in different cancer models. $I R F 1$ was very recently associated to mesenchymal features, basal like and CLAUDINlow BC [32], data which are in agreement with our results showing that this gene was associated to TNBC. IRF1 regulates autophagy induction but is not directly involved in the autophagy process, and it participates in numerous pathways which may explain why its expression is associated with a good prognosis in $\mathrm{BC}$ patients despite its association with TNBC. These data were also supported by the observation reporting that an induction of IRFI expression in BC cells provoked apoptotic cell death [33]. Indeed, although some of these genes have previously been associated to $\mathrm{BC}$, to our knowledge, none of these previous reports used metadata analysis including several thousands of patients and 4 independent analyses. Altogether, these data strongly showed that our BC signature using the systematic quantification of $A T G 2 B$, $B E C N 1, L C 3 B, A T G 5$, and eventually $U L K 1$ and $I R F 1$ led to a robust discrimination of $\mathrm{BC}$ subgroups and helped for prognosis.

Since autophagy is a dynamic process formed by the formation and the degradation of autophagosomes, induction of autophagy as well as disruption of the autophagy flux may both provoke autophagosome and ATG protein accumulation leading to a difficult quantification of the autophagy flux in fixed biopsies by IHC. Therefore, a better understanding of autophagy mechanisms is a major point to develop future personalized therapies based on autophagy-targeting drugs. Quantification of autophagy gene expressions could therefore be appropriate to determine autophagy levels in biopsy samples. We described that the quantification of $A T G 2 B, A T G 5, L C 3 B$ expressions would help to determine autophagy levels, but since these genes were associated to a specific BC group, we also looked for an independent marker. Amongst the genes whose expression was the most increased following autophagy induction in cells treated by EBSS (Figure 6A), TXNIP appeared as a good candidate for a biomarker of autophagy induction. Even if the protein TXNIP is not directly involved in autophagy flux, the regulation of its expression is, at least partly, independent of autophagosome number and may well reflect autophagy levels. Indeed, this protein has previously been associated to autophagy by Shui Qiao et $a l$. who reported a direct role of TXNIP in the regulation of ATG4B activity as well as autophagy induction [34]. Moreover, an increase in TXNIP expression was progressive (Figure 6B-6C) suggesting that a correlation could be established between the level of autophagy and the level of TXNIP expression. Based on TXNIP expression and the fact that a blockage of autophagy promoted cell migration (Figure 5), our data argued that autophagy induction and initiation limited aggressiveness but that individual $A T G$ genes, such as $A T G 5$ and $L C 3 B$, might promote cancer-related phenotypes in a possible autophagy-independent manner.

In conclusion, our work demonstrated, for the first time, that the quantification of specific autophagy genes, such as BECN1, ATG5, LC3B, ATG2B and TXNIP, could help in establishing a new BC stratification in the future and developing new autophagy-linked therapies.

\section{MATERIALS AND METHODS}

\section{Patients}

Human samples were collected according to French laws and the recommendations of the French National Committee of Ethics. This study has been approved by the scientific committee of "the Tumorothèque Régionale de Franche-Comté BB-0033-00024". All human samples were collected by the Hospital of Besançon (France) at the "Tumorothèque Régionale de Franche-Comté BB0033-00024". Collection of samples and their use (AC2010-1163) for studies have been approved by the French "Ministère de la Recherche" and by the CPP EST II. We obtained all necessary consents from any patients involved in the study.

\section{Cell culture}

MCF-7 and MDA-MB-231 cells were respectively cultured in DMEM low glucose (Dutscher) supplemented with 5 or $10 \%$ SVF (Dutscher) and 1\% penicillinstreptomycin (Dutscher) with $5 \% \mathrm{CO}_{2}$ in an atmosphere saturated in humidity. Plasmids for overexpression of BECN1 (gift from Dr G. Kroemer), GFP-LC3B (gift from Dr. Elazar, The Weizmann Institute of Science, Rehovot, Israel), GFP-ATG2B (gift from Dr Li Yu [35]), ATG5 (\#24922, addgene) or empty vector were transfected using JetPrime reagent (114, Polyplus) according to the manufacturer's instructions. The inhibition of gene expression was performed using siRNA (Eurogentec) and Interferin (409, Polyplus) according to the manufacturer's recommendations. When indicated, cells were treated with EBSS (E3024, Invitrogen) for 2 to $24 \mathrm{~h}$ or $500 \mathrm{nM}$ BafA1 
(B1793, Sigma-Aldrich) for $2 \mathrm{~h}$.

\section{Cell proliferation and wound healing assay}

Cell proliferation was analyzed using the Incucyte automatic microscope (Sartorius) following cell seeding (4,000 for MCF-7 and 2,000 for MDA-MB-231). Migration assays were performed using culture-insert 2 wells in $35 \mathrm{~mm}$ microdishes (81176, Ibidi). 30,000 pretreated cells were plated in each well and the insert was removed $24 \mathrm{~h}$ later. Migration was monitored for $8 \mathrm{~h}$.

\section{Western-blotting}

Total protein extracts were obtained from scraped cells which were harvested and lysed for $30 \mathrm{~min}$ on ice in RIPA buffer (50 mM Tris-HCl, pH 8, $150 \mathrm{mM} \mathrm{NaCl}, 1 \%$ Triton X100, 0.5\% DOCA, 0.1\% SDS) supplemented with protease inhibitors (104 mM AEBSF, $1.5 \mathrm{mM}$ pepstatin A, $1.4 \mathrm{mM}$ E-64, $4 \mathrm{mM}$ bestatin, $2 \mathrm{mM}$ leupeptin, $80 \mu \mathrm{M}$ aprotinin). $20-40 \mu \mathrm{g}$ of total proteins were separated on TGX acrylamide gels (1610172, Biorad) at $280 \mathrm{~V}$ for about 30 min using Biorad Protean III system and transferred onto PVDF (1704157, Bio-Rad) membranes for $10 \mathrm{~min}$ with the Transblot turbo (1704150, Biorad) according to the manufacturer's recommendations. Membranes were saturated in $0.1 \%$ TBS-Tween 20 and $5 \%$ milk for $1 \mathrm{~h}$ and then incubated with primary antibodies anti-LC3B (L8918, Sigma-Aldrich), anti-ACTIN (A5060, Sigma-Aldrich) overnight at $4{ }^{\circ} \mathrm{C}$. Membranes were washed 3 times with TBS-Tween $200.1 \%$, incubated with secondary anti-rabbit HRP conjugate antibodies according to manufacturer's instructions (P.A.R.I.S.). (BI2407, BI2413C, P.A.R.I.S.). Membranes were washed 3 times with TBS-Tween 20 $0.1 \%$ and incubated with Clarity Western $\mathrm{Cl}$ substrate (1705051, Biorad) and chemiluminescence was monitored using a Biorad ChemiDoc ${ }^{\mathrm{TM}}$ XRS+.

\section{Transcriptomes, qRT-PCR and Droplet Digital RT-PCR}

RNA was isolated from cells using the Tri Reagent (TR118, Molecular Research Center) as recommended by the manufacturer and as previously described [36]. Reverse transcription was performed using $12 \mathrm{U}$ M-MLV reverse transcriptase (M-1302, Sigma-Aldrich), 0.25 $\mu \mathrm{M}$ oligodT (Eurogentec), $1.25 \mu \mathrm{M}$ random hexamers (C118A, Promega) and $1.5 \mu \mathrm{g}$ total RNA according to the manufacturer's instructions (Sigma-Aldrich). Primers (Eurogentec) were designed using the primer 3 software: ULK1: 5'-CAGACAGCCTGATGTGCAGT-3' and 5'-TCAATGCGCTGGTAGTTCTG-3', LC3B: 5'-TTGAGCTGTAAGCGCCTTCT-3' and 5'AGCAGCATCCAACCAAAATC-3',
ATG5:

and

IRF1:

and

ATG2B:

and

$B E C N 1$ :

and

$T B P$ :

and

Ki67:

and quantification of cDNA was performed using the QX200 Droplet Digital PCR system (ddPCR, Biorad) with the QX200 ddPCR EvaGreen Supermix (1864033, Biorad) according to the manufacturer's instructions. Absolute quantification was performed using the QuantaSoft ${ }^{\mathrm{TM}}$ Software (BioRad). Quantitative PCR (qPCR) were performed as duplicates using the Step one plus RealTime PCR system (Applied Biosystems, France) and the Premix Ex Taq ${ }^{\mathrm{TM}}$ DNA Polymerase kit (RR039B, Takara) according to the manufacturer's recommendations. RNAseq was performed in MDA-MB-231 cells by Integragen society.

\section{Statistics}

Two distinct Affymetrix series were built following GC-RMA normalization: one from HG-U133A arrays $(n$ $=2806)$ and one from HG-U133 plus2 arrays $(n=2691)$ in which 6500 additional probes were added. Each serie was standardized using the Aroma R package which was developed to normalize multicenter extremely large Affymetrix data sets. The same computations were performed in the two data sets in order to cross-validate the results. Samples were classified with a reduced number of genes (as described in the St Gallen classification [3739]) and with classifiers using 50 or more than 300 genes (PAM50, CIT and IntClust centroids). Transcriptome analysis was performed using the $\mathrm{R}$ software version 3.3.1 from the R Foundation for Statistical Computing (Vienna, Austria). Transcriptomes were analyzed from Affymetrix series (GPL570 platform) after GC-RMA normalization. 2830 samples were used from the following GEO series: GSE12276, GSE12790, GSE18931, GSE2109, GSE22035, GSE23720, GSE23994, GSE25407, GSE26910, GSE30010, GSE3744, GSE5764, GSE17700, GSE26639, GSE16446, GSE18864, GSE22513, GSE19615, GSE20685, GSE21653, GSE23177, GSE9195, GSE6532. Samples were classified using the PAM50 method using 50 genes (Genefu R package). For RNA-seq, TCGA data analysis was performed using 1222 samples. Differences between means for each cell experiment were performed using the t-test and the 
GraphPad software. The expression score was calculated as follow: sum of (individual score values from IRF1, $L C 3 B, A T G 5$ ) minus (individual score values of $A T G 2 B$, $B C N 1)$. Each individual score value was calculated from -6 to 6 depending of the level of intensity.

\section{ABBREVIATIONS}

BL-1/2 - basal-like

$\mathrm{BC}$ - (breast cancer)

LumA/B - (luminal A or B)

BafA1 - (bafilomycin A1)

TNBC - (triple negative breast cancer)

ULK1 and 2 - (Unc-51 Like Autophagy Activating Kinase 1 and 2)

\section{ACKNOWLEDGMENTS}

We thank the biobank Tumorothèque of FrancheComté for providing the biopsy samples, the EPIGENExp platform for ddPCR experiments and the DimaCell platform for Incucyte experiments. We also thank our financial supports: "La Ligue Contre le Cancer", la région "Bourgogne Franche-Comté" and le "Cancéropôle Grand Est".

\section{AUTHOR CONTRIBUTIONS}

Céline Grandvallet: literature search, data collection, data analysis, study design

Jean Paul Feugeas: data collection, data analysis, data interpretaion

Franck Monnien: data collection

Gilles Despouy: data interpretation and analysis

Valérie Perez: data collection

Michaël Perez: data interpretation and analysis

Eric Hervouet: data collection, data analysis, study design, data interpretaion, writing

Paul Peixoto: data collection, data analysis, study design, data interpretaion, writing

\section{CONFLICT OF INTEREST}

There is no conflict of interest.

\section{REFERENCES}

1. Behrends C, Sowa ME, Gygi SP, Harper JW. Network organization of the human autophagy system. Nature. 2010; 466:68-76. https://doi.org/10.1038/nature09204. PMID:20562859

2. Zaffagnini G, Martens S. Mechanisms of Selective Autophagy. J Mol Biol. 2016; 428:1714-24. https://doi.org/10.1016/j. imb.2016.02.004. PMID:26876603
3. Liang C, Feng P, Ku B, Dotan I, Canaani D, Oh BH, Jung JU. Autophagic and tumour suppressor activity of a novel Beclin1-binding protein UVRAG. Nat Cell Biol. 2006; 8:688-99. https://doi.org/10.1038/ncb1426. PMID:16799551

4. Liang XH, Jackson S, Seaman M, Brown K, Kempkes B, Hibshoosh H, Levine B. Induction of autophagy and inhibition of tumorigenesis by beclin 1 . Nature. 1999; 402:672-76. https://doi.org/10.1038/45257. PMID:10604474

5. Claude-Taupin A, Boyer-Guittaut M, Delage-Mourroux R, Hervouet E. Use of epigenetic modulators as a powerful adjuvant for breast cancer therapies. Methods Mol Biol. 2015; 1238:487-509. https://doi.org/10.1007/978-1-49391804-1 25. PMID:25421676

6. Cook KL, Shajahan AN, Clarke R. Autophagy and endocrine resistance in breast cancer. Expert Rev Anticancer Ther. 2011; 11:1283-94. https://doi.org/10.1586/era.11.111. PMID:21916582

7. Vera-Ramirez L, Vodnala SK, Nini R, Hunter KW, Green JE. Autophagy promotes the survival of dormant breast cancer cells and metastatic tumour recurrence. Nat Commun. 2018; 9:1944. https://doi.org/10.1038/s41467-018-040706. PMID:29789598

8. Zhao H, Yang M, Zhao J, Wang J, Zhang Y, Zhang Q. High expression of LC3B is associated with progression and poor outcome in triple-negative breast cancer. Med Oncol. 2013; 30:475. https://doi.org/10.1007/s12032-013-0475-1. PMID:23371253

9. Lefort S, Joffre C, Kieffer Y, Givel AM, Bourachot B, Zago G, Bieche I, Dubois T, Meseure D, Vincent-Salomon A, Camonis J, Mechta-Grigoriou F. Inhibition of autophagy as a new means of improving chemotherapy efficiency in high-LC3B triple-negative breast cancers. Autophagy. 2014; 10:2122-42. https://doi.org/10.4161/15548627.2014.98178 8. PMID:25427136

10. Chen S, Jiang YZ, Huang L, Zhou RJ, Yu KD, Liu Y, Shao ZM. The residual tumor autophagy marker LC3B serves as a prognostic marker in local advanced breast cancer after neoadjuvant chemotherapy. Clin Cancer Res. 2013; 19:6853-62. https://doi.org/10.1158/1078-0432.CCR-131617. PMID:24141623

11. Cicchini M, Chakrabarti R, Kongara S, Price S, Nahar R, Lozy F, Zhong H, Vazquez A, Kang Y, Karantza V. Autophagy regulator BECN1 suppresses mammary tumorigenesis driven by WNT1 activation and following parity. Autophagy. 2014; 10:2036-52. https://doi. org/10.4161/auto.34398. PMID:25483966

12. Berthier A, Seguin S, Sasco AJ, Bobin JY, De Laroche G, Datchary J, Saez S, Rodriguez-Lafrasse C, Tolle F, Fraichard A, Boyer-Guittaut M, Jouvenot M, DelageMourroux R, Descotes F. High expression of gabarapl1 is associated with a better outcome for patients with lymph node-positive breast cancer. Br J Cancer. 2010; 102:1024- 
31. https://doi.org/10.1038/sj.bjc.6605568. PMID:20197771

13. Poillet-Perez L, Jacquet M, Hervouet E, Gauthier T, Fraichard A, Borg C, Pallandre JR, Gonzalez BJ, Ramdani Y, Boyer-Guittaut M, Delage-Mourroux R, Despouy G. GABARAPL1 tumor suppressive function is independent of its conjugation to autophagosomes in MCF-7 breast cancer cells. Oncotarget. 2017; 8:55998-6020. https://doi. org/10.18632/oncotarget.19639. PMID:28915569

14. Boyer-Guittaut M, Poillet L, Liang Q, Bôle-Richard E, Ouyang X, Benavides GA, Chakrama FZ, Fraichard A, Darley-Usmar VM, Despouy G, Jouvenot M, DelageMourroux R, Zhang J. The role of GABARAPL1/GEC1 in autophagic flux and mitochondrial quality control in MDAMB-436 breast cancer cells. Autophagy. 2014; 10:9861003. https://doi.org/10.4161/auto.28390. PMID:24879149

15. Zhang Y, Wang F, Han L, Wu Y, Li S, Yang X, Wang Y, Ren F, Zhai Y, Wang D, Jia B, Xia Y, Chang Z. GABARAPL1 negatively regulates $\mathrm{Wnt} / \beta$-catenin signaling by mediating Dv12 degradation through the autophagy pathway. Cell Physiol Biochem. 2011; 27:503-12. https://doi. org/10.1159/000329952. PMID:21691068

16. Hervouet E, Claude-Taupin A, Gauthier T, Perez V, Fraichard A, Adami P, Despouy G, Monnien F, Algros MP, Jouvenot M, Delage-Mourroux R, Boyer-Guittaut M. The autophagy GABARAPL1 gene is epigenetically regulated in breast cancer models. BMC Cancer. 2015; 15:729. https://doi. org/10.1186/s12885-015-1761-4. PMID:26474850

17. Parker JS, Mullins M, Cheang MC, Leung S, Voduc D, Vickery T, Davies S, Fauron C, He X, Hu Z, Quackenbush JF, Stijleman IJ, Palazzo J, et al. Supervised risk predictor of breast cancer based on intrinsic subtypes. J Clin Oncol. 2009; 27:1160-67. https://doi.org/10.1200/ JCO.2008.18.1370. PMID:19204204

18. Neve RM, Chin K, Fridlyand J, Yeh J, Baehner FL, Fevr T, Clark L, Bayani N, Coppe JP, Tong F, Speed T, Spellman PT, DeVries S, et al. A collection of breast cancer cell lines for the study of functionally distinct cancer subtypes. Cancer Cell. 2006; 10:515-27. https://doi.org/10.1016/j. ccr.2006.10.008. PMID:17157791

19. Fekete JT, Györffy B. ROCplot.org: validating predictive biomarkers of chemotherapy/hormonal therapy/anti-HER2 therapy using transcriptomic data of 3,104 breast cancer patients. Int J Cancer. 2019; 145:3140-51. https://doi. org/10.1002/ijc.32369. PMID:31020993

20. Liang XH, Yu J, Brown K, Levine B. Beclin 1 contains a leucine-rich nuclear export signal that is required for its autophagy and tumor suppressor function. Cancer Res. 2001; 61:3443-49. PMID:11309306

21. Yao Q, Chen J, Lv Y, Wang T, Zhang J, Fan J, Wang L. The significance of expression of autophagy-related gene Beclin, Bcl-2, and Bax in breast cancer tissues. Tumour Biol. 2011; 32:1163-71. https://doi.org/10.1007/s13277011-0219-9. PMID:21861179

22. Tang H, Sebti S, Titone R, Zhou Y, Isidoro C, Ross TS, Hibshoosh H, Xiao G, Packer M, Xie Y, Levine B.
Decreased BECN1 mRNA Expression in Human Breast Cancer is Associated with Estrogen Receptor-Negative Subtypes and Poor Prognosis. EBioMedicine. 2015; 2:255-63. https://doi.org/10.1016/j.ebiom.2015.01.008. PMID:25825707

23. He Y, Zhao X, Subahan NR, Fan L, Gao J, Chen H. The prognostic value of autophagy-related markers beclin-1 and microtubule-associated protein light chain $3 \mathrm{~B}$ in cancers: a systematic review and meta-analysis. Tumour Biol. 2014; 35:7317-26. https://doi.org/10.1007/s13277-014-2060-4. PMID:24838948

24. Zhang X, Li C, Wang D, Chen Q, Li CL, Li HJ. Aberrant methylation of ATG2B, ATG4D, ATG9A and ATG9B $\mathrm{CpG}$ island promoter is associated with decreased mRNA expression in sporadic breast carcinoma. Gene. 2016; 590:285-92. https://doi.org/10.1016/j.gene.2016.05.036. PMID:27265029

25. Kang MR, Kim MS, Oh JE, Kim YR, Song SY, Kim SS, Ahn $\mathrm{CH}$, Yoo NJ, Lee SH. Frameshift mutations of autophagyrelated genes ATG2B, ATG5, ATG9B and ATG12 in gastric and colorectal cancers with microsatellite instability. J Pathol. 2009; 217:702-06. https://doi.org/10.1002/ path.2509. PMID: 19197948

26. Choi J, Jung W, Koo JS. Expression of autophagy-related markers beclin-1, light chain 3A, light chain 3B and p62 according to the molecular subtype of breast cancer. Histopathology. 2013; 62:275-86. https://doi.org/10.1111/ his.12002. PMID:23134379

27. Pandya V, Glubrecht D, Vos L, Hanson J, Damaraju S, Mackey J, Hugh J, Goping IS. The pro-apoptotic paradox: the $\mathrm{BH} 3$-only protein $\mathrm{Bcl}-2$ interacting killer (Bik) is prognostic for unfavorable outcomes in breast cancer. Oncotarget. 2016; 7:33272-85. https://doi.org/10.18632/ oncotarget.8924. PMID:27120789

28. Wang L, Yao L, Zheng YZ, Xu Q, Liu XP, Hu X, Wang P, Shao ZM. Expression of autophagy-related proteins ATG5 and FIP200 predicts favorable disease-free survival in patients with breast cancer. Biochem Biophys Res Commun. 2015; 458:816-22. https://doi.org/10.1016/j. bbrc.2015.02.037. PMID:25689718

29. Lian Y, Xie Y, Hong M, Zhu Y, Zhao H, Zhao X, Zhu H, Qiao C, Li J, Qian S. Clinical significance of BECLIN1 and ATG5 expression in acute myeloid leukemia patients. Int J Clin Exp Pathol. 2018; 11:1529-37. PMID:31938250

30. Yu K, Xiang L, Li S, Wang S, Chen C, Mu H. HIF1 $\alpha$ promotes prostate cancer progression by increasing ATG5 expression. Anim Cells Syst (Seoul). 2019; 23:32634. $\quad$ https://doi.org/10.1080/19768354.2019.1658637. PMID:31700698

31. Huang S, Qi P, Zhang T, Li F, He X. The HIF-1 $\alpha /$ miR-224-3p/ ATG5 axis affects cell mobility and chemosensitivity by regulating hypoxia-induced protective autophagy in glioblastoma and astrocytoma. Oncol Rep. 2019; 41:175968. PMID:30569180

32. Meyer-Schaller N, Tiede S, Ivanek R, Diepenbruck M, 
Christofori G. A dual role of Irf1 in maintaining epithelial identity but also enabling EMT and metastasis formation of breast cancer cells. Oncogene. 2020; 39:4728-40. https:// doi.org/10.1038/s41388-020-1326-0. PMID:32404986

33. Armstrong MJ, Stang MT, Liu Y, Yan J, Pizzoferrato E, Yim JH. IRF-1 inhibits NF- $\kappa$ B activity, suppresses TRAF2 and cIAP1 and induces breast cancer cell specific growth inhibition. Cancer Biol Ther. 2015; 16:1029-41. https://doi. org/10.1080/15384047.2015.1046646. PMID:26011589

34. Qiao S, Dennis M, Song X, Vadysirisack DD, Salunke D, Nash Z, Yang Z, Liesa M, Yoshioka J, Matsuzawa S, Shirihai OS, Lee RT, Reed JC, Ellisen LW. A REDD1/ TXNIP pro-oxidant complex regulates ATG4B activity to control stress-induced autophagy and sustain exercise capacity. Nat Commun. 2015; 6:7014. https://doi. org/10.1038/ncomms8014. PMID:25916556

35. Zheng JX, Li Y, Ding YH, Liu JJ, Zhang MJ, Dong MQ, Wang HW, Yu L. Architecture of the ATG2B-WDR45 complex and an aromatic Y/HF motif crucial for complex formation. Autophagy. 2017; 13:1870-83. https://doi.org/1 0.1080/15548627.2017.1359381. PMID:28820312

36. Claude-Taupin A, Fonderflick L, Gauthier T, Mansi L, Pallandre JR, Borg C, Perez V, Monnien F, Algros MP, Vigneron M, Adami P, Delage-Mourroux R, Peixoto P, et al. ATG9A Is Overexpressed in Triple Negative Breast Cancer and Its In Vitro Extinction Leads to the Inhibition of Pro-Cancer Phenotypes. Cells. 2018; 7:E248. https://doi. org/10.3390/cells7120248. PMID:30563263

37. Guedj M, Marisa L, de Reynies A, Orsetti B, Schiappa R, Bibeau F, MacGrogan G, Lerebours F, Finetti P, Longy M, Bertheau P, Bertrand F, Bonnet F, et al. A refined molecular taxonomy of breast cancer. Oncogene. 2012; 31:1196-206. https://doi.org/10.1038/onc.2011.301. PMID:21785460

38. Ali HR, Rueda OM, Chin SF, Curtis C, Dunning MJ, Aparicio SA, Caldas C. Genome-driven integrated classification of breast cancer validated in over 7,500 samples. Genome Biol. 2014; 15:431. https://doi.org/10.1186/s13059-0140431-1. PMID:25164602

39. Wallden B, Storhoff J, Nielsen T, Dowidar N, Schaper C, Ferree S, Liu S, Leung S, Geiss G, Snider J, Vickery T, Davies SR, Mardis ER, et al. Development and verification of the PAM50-based Prosigna breast cancer gene signature assay. BMC Med Genomics. 2015; 8:54. https://doi. org/10.1186/s12920-015-0129-6. PMID:26297356 